\title{
Stereotactic Radiosurgery of a Patient with Severe Kyphosis
}

\author{
Donald A. Ross, ${ }^{1,3}$ Howard M. Sandler, ${ }^{2}$ James M. Balter, ${ }^{2}$ and David Hornick ${ }^{2}$
}

A patient with a severe kyphotic deformity presented for stereotactic radiosurgery. In the supine position with the apex of the patient's kyphosis on the treatment couch, his head and buttocks were found to be approximately $30 \mathrm{~cm}$ from the table. Pretreatment consultation with the physicist and engineer was arranged. By creating a modified table mount for the head ring and a custommolded Styrofoam cradle for the patient's pelvis, radiosurgery in the supine position was carried out without difficulty or patient discomfort. We describe the technical aspects of the treatment.

KEY WORDS: Stereotactic radiosurgery; kyphosis; linear accelerator; multileaf collimator.

\section{INTRODUCTION}

A patient with a severe kyphotic deformity of the thoracic spine presented for stereotactic radiosurgical treatment of an enlarging acoustic neuroma. The patient's body habitus made it impossible to deliver conventional treatment in the supine position by fixation of the stereotactic head ring to the computed tomography (CT) table and treatment couch. Pretreatment consultation with the radiation physicist and engineer allowed the derivation of a suitable modification of the treatment couch to allow successful treatment. We report the technique utilized.

The patient is a 73-year-old man with coronary artery disease who noted the gradual onset of hearing loss in the right ear and a tendency to fall to the right. Examination revealed difficulty with Romberg testing and tandem walking due to falling to the right and hearing loss in the right ear. The patient was noted to be

\footnotetext{
'Department of Surgery, Section of Neurosurgery, University of Michigan Medical Center, Ann Arbor, Michigan 48109.

${ }^{2}$ Department of Radiation Oncology, University of Michigan Medical Center, Ann Arbor, Michigan 48109.

${ }^{3}$ To whom correspondence should be addressed at Section of Neurosurgery, University of Michigan Medical Center, 1500 East Medical Center Drive, Box 0338, Ann Arbor, Michigan 48109.
}

markedly kyphotic, which he reported had progressed gradually over many years (Fig. 1). Magnetic resonance imaging (MRI) revealed a typical acoustic neuroma with an anterior-posterior diameter of $24 \mathrm{~mm}$ and a maximum dimension from the fundus to the brain stem of $32 \mathrm{~mm}$.

\section{METHODS}

The patient opted for stereotactic radiosurgical treatment of his tumor. Because his kyphosis was severe, pretreatment evaluation by the radiosurgery program physicist and engineer was arranged. With the apex of the patient's kyphosis on the treatment couch, his head and buttocks were found to be approximately $30 \mathrm{~cm}$ above the table (the attachment point for the head ring has a normal range of 17 to $20 \mathrm{~cm}$ above the table, which can be increased to $25 \mathrm{~cm}$ through the use of extended mounting brackets). In order to secure the stereotactic head ring to the treatment couch, the table mount for the head ring (Radionics, Burlington, MA) was modified by utilizing the long mounting brackets supplied by the manufacturer, which were then raised an additional $7 \mathrm{~cm}$ by the imposition of two Lucite block between the brackets and the base (Fig. 2). This arrangement does not alter the isocenter but lowers the 


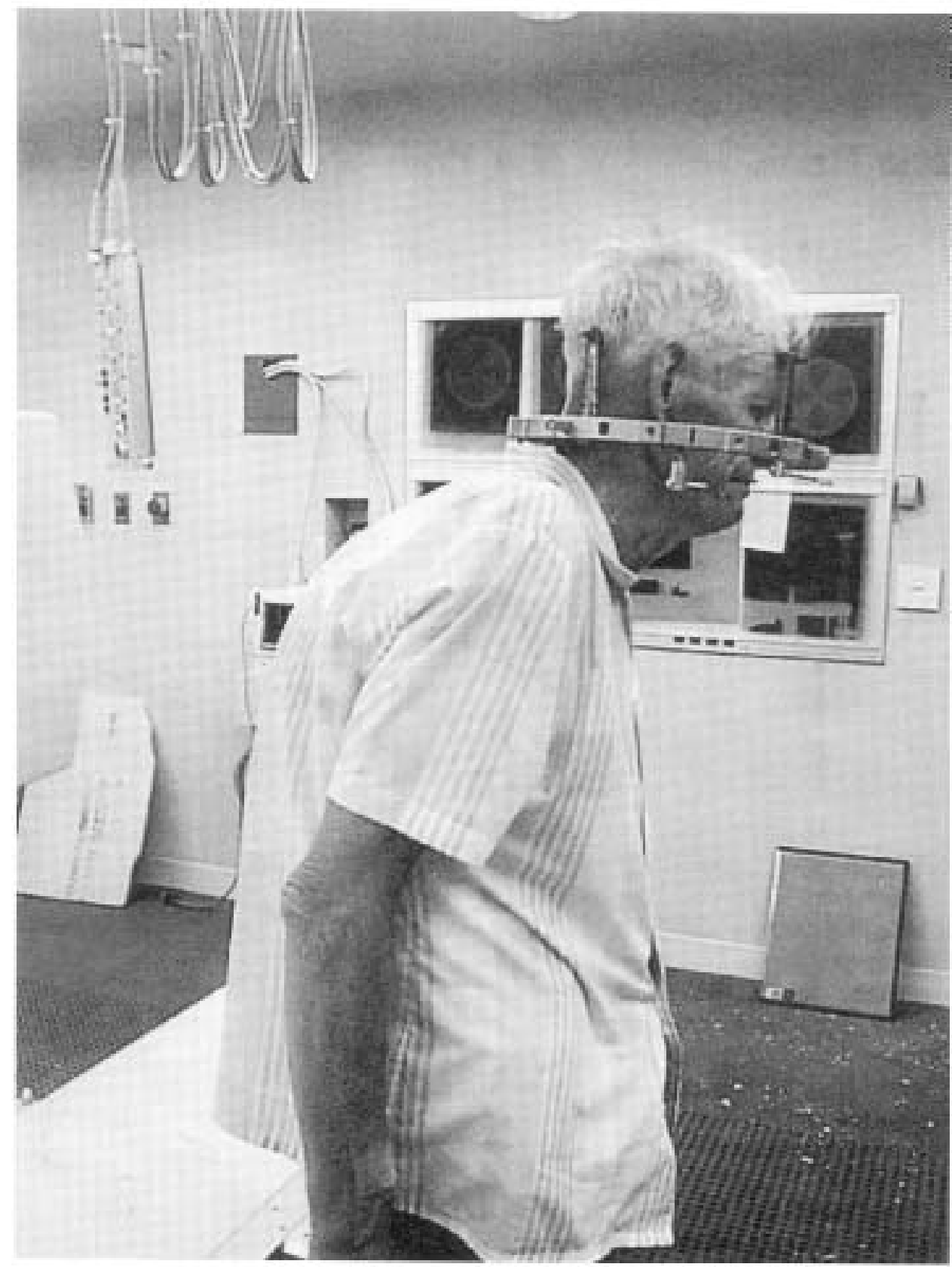

Fig. 1. Side view of patient showing markedly kyphotic spine.

table position required to bring the frame to the isocenter. A machinist's level was used to confirm that this did not introduce any unintended flex in the immobilizer. To support the patient's buttocks during treatment, a custom-molded cradle similar to those used for conventional fractionated radiation therapy (1) was made (Fig. 3).

\section{RESULTS}

After verifying that no large rotations in the frame position were noted on the CT scan, the foam cradle was utilized to position the patient in the CT scanner. With the modifications described, the patient was then treated using an accelerator fitted with a multileaf collimator 


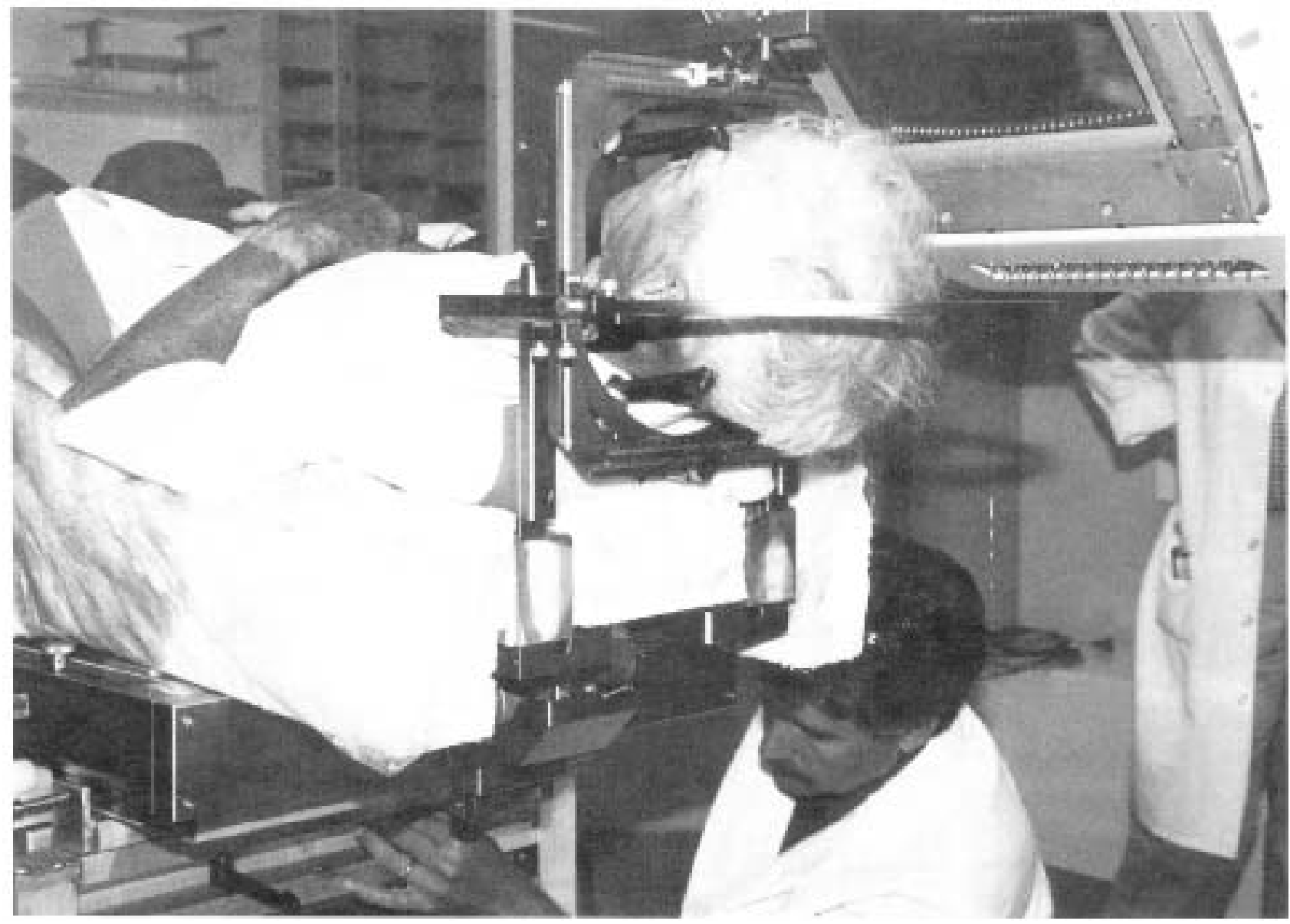

Fig. 2. Long extension brackets and additional Lucite blocks used to raise the table attachment to the BRW head ring to accommodate the patient's kyphotic deformity.

and computer-controlled radiotherapy system (2). Our system uses a Radionics BRW stereotactic head frame with a custom adapter to the treatment couch and a Scanditronix MM50 Racetrack Microtron accelerator fitted with a multileaf collimator (Scanditronix, Uppsala, Sweden). The patient's head is rigidly affixed to the treatment couch by a mounting bracket. A film-based paradigm is used to verify that orthogonal positioning lasers are accurate, then these lasers are used to position the isocenter, which is confirmed prior to treatment by orthogonal radiographs and measurement of source-tosurface distances (3). A single isocenter was used to deliver 14 Gray to the $82 \%$ isodose surface using 3 pseudoarcs composed of 15 static-shaped treatment fields. Setup and verification of patient position took about 45 minutes. Treatment required an additional 30 minutes. During this period, the patient reported no discomfort.

\section{DISCUSSION}

Kyphotic patients present difficulties for framebased stereotactic procedures, as attachment of the frame to the CT, MR, or radiotherapy couch requires that the patient lie flat in the supine, or occasionally prone, position with the neck in a neutral position with respect to the thorax. This problem has become common in the stereotactic imaging of kyphotic Parkinson's disease patients being treated with stereotactic pallidotomy, for whom the problem is often solved by elevating the buttocks or imaging without the head coil with the frame supported on padding (personal experience of DAR). The patient's kyphosis was too severe for simple elevation of the buttocks and the requirement for proper positioning of the isocenter obviates treatment without the frame firmly attached to the treatment couch. 


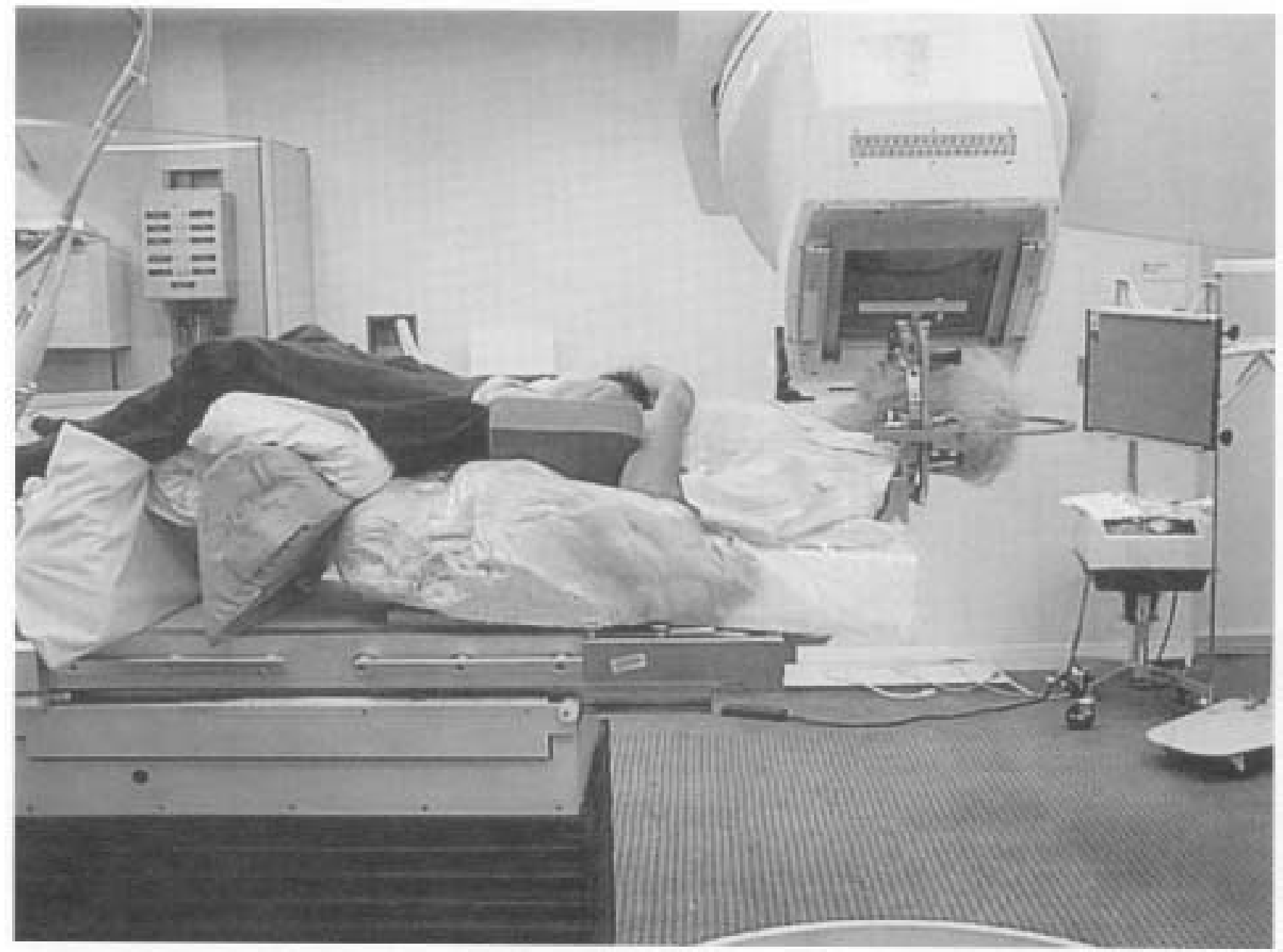

Fig. 3. Styrofoam cradle used to support the patient's hips and buttocks during treatment.

An alternative for this patient would have been treating in the prone position, which has been utilized successfully for stereotactic biopsy in the posterior fossa using the BRW frame (4). However, extensive padding would still have been required to maintain the patient's neck in a comfortable position and the face-down position is generally less well tolerated by awake patients. Elevation of the mounting brackets and use of a Styrofoam cradle allowed comfortable treatment in the supine position.

\section{REFERENCES}

1. Bentel GC: Radiation Therapy Planning, 2nd ed. New York, McGraw-Hill, 1996, pp 332-335

2. Balter J, Martel M, Sandler H, Ross D, Forster K, McShan D, Fraass B, Ten Haken R: Clinical implementation of radiosurgery using a multileaf collimator and a computer controlled radiotherapy system. Int J Radiat Oncol Biol Phys 32(suppl 1):169, 1995

3. Schell MC, Bova FJ, Larson DA, Leavitt DD, Lutz WR, Podgorsak EB, Wu A: Stereotactic Radiosurgery, AAPM Report No. 54, Woodbury, New York, American Institute of Physics, 1995, pp 30-32

4. Guthrie BL, Steinberg GK, Adler JR: Posterior fossa stereotaxic biopsy using the Brown-Roberts-Wells stereotaxic system. I Neurosurg 70:649-652, 1989 